
p. 84-87, março 2003 .

\title{
Desempenho de três cultivares de almeirão sob cultivo protegido
}

\author{
Maria do Carmo S.S. Novo ${ }^{1}$; Paulo E. Trani ${ }^{1}$; Keigo Minami ${ }^{2}$ \\ ${ }^{1}$ IAC, C. Postal 28, 13.001-970, Campinas-SP, E-mail: mcdesalvo@ hotmail.com; ${ }^{2}$ USP-ESALQ, C. Postal 9, 13.418-900 Piracicaba-SP
}

\begin{abstract}
RESUMO
O almeirão (Cichorium intybus L.) é uma Asteraceae muito semelhante à chicória da qual se diferencia por possuir folhas mais alongadas, mais estreitas, recobertas por pelos e com sabor amargo mais pronunciado. Avaliou-se o desempenho das cultivares Folha Larga, Pão-de-Açúcar e Catalonha, em estufa com cobertura plástica, em experimento, de julho a setembro/2001, no Núcleo Experimental de Campinas do IAC. O experimento foi disposto em blocos ao acaso, com parcelas subdivididas para época de avaliação, tendo três repetições. Aos 50; 57; 64 e 71 dias após a semeadura foram avaliadas dez plantas de cada subparcela quanto à altura, número médio de folhas, biomassas de matéria fresca e seca e área foliar. Nessas oportunidades foram também avaliadas as produções de folhas em um metro linear de canteiro. Não houve diferença entre as cultivares quanto ao número médio de folhas por planta porém houve interação entre cultivares e época de avaliação para área foliar, biomassas fresca e seca e produção de folhas. A cultivar Catalonha foi a que apresentou maior altura e maior produtividade, embora as biomassas de matéria fresca e seca tenham sido superiores na Pãode-Açúcar que também apresentou maior área foliar. Recomendase, com base na área foliar, a colheita dessas hortaliças até os 64 dias. Concluiu-se que foi viável a produção de almeirão sob cultivo protegido constituindo-se em mais uma alternativa para esse sistema de produção.
\end{abstract}

Palavras-chave: Cichorium intybus L., produção, área foliar, cultivo protegido.

\begin{abstract}
Performance of three chicory cultivars grown in greenhouse

Cichorium intibus L. is an Asteraceae very similar to endive, distinguished by longer and narrower leaves covered with pile and bitter flavored. An experiment was carried out in a plastic greenhouse, to evaluate the performance of the Folha Larga, Pão-de-Açúcar and Catalonha cultivars, from July to September/2001, at IAC, Campinas, Brazil. A split plot design was used with the cultivars in the main plots and sampling data as subplots. Each main plot and subplot was randomized in three replications. At 50; 57; 64 and 71 days after sowing, ten plants of each subplot were taken and their height, leaf number, foliar area and fresh and dry matter weight were measured. Yield of leaves per linear meter was also evaluated. No difference in leaf number per plant was observed but interaction was found among cultivars and time of evaluation for foliar area, and fresh and dry matter weight. Catalonha was the tallest and more yielding cultivar but Pão-de-Açucar presented the highest values of fresh and dry matter weight. Pão-de-Açúcar also presented highest foliar area. Based on foliar area, chicory should be harvested withing 64 days after sowing date. Obtained data indicate that chicory, cultivated in a plastic greenhouse, is a new and good alternative to this production system.
\end{abstract}

Keywords: Cichorium intybus, yield, leaf area, protected cultivation.

(Recebido para publicação em 09 de janeiro de 2002 e aceito em 13 de setembro de 2002)

$C^{\prime}$ ichorium intybus L. é uma Asteraceae muito semelhante à chicória de quem se diferencia por possuir folhas mais alongadas, mais estreitas, recobertas por pelos e com sabor amargo mais pronunciado (Filgueira, 2000). Camargo (1992) descreveu como as cultivares mais cultivadas: Folha Larga, Branco e Pão-de-Açúcar. Trani \& Passos (1998) incluem também uma cultivar de folha dentada denominado Catalonha entre as mais cultivadas. Segundo Hangui ${ }^{3}$ as cultivares Folha Larga, Pão-de-Açúcar e Catalonha são as mais cultivadas na região de Campinas. Segundo o Instituto de Economia Agrícola e a Coordenadoria de Assistência Técnica Integral, publicados por Camargo \& Camargo (1999), a produção, produtividade e a área cultivada da
'Catalonha' são apresentadas separadamente das de almeirão. Segundo esses autores, as áreas cultivadas com almeirão e com 'Catalonha', no estado de São Paulo, para o ano de 1998, foram respectivamente, de 960 e 546 hectares. Embora do ponto de vista nutricional o almeirão seja superior à alface (Khathounian, 2001) por ser mais calórico e mais rico em proteínas, amido, fibras, cálcio, ferro e vitamina A, é uma das hortaliças menos estudadas no Brasil quanto ao comportamento das cultivares mais comercializadas. Não foi encontrado, para as condições brasileiras, trabalho de pesquisa referente a almeirão na década de noventa. Os únicos trabalhos de pesquisa para almeirão mais recentes foram os de Matsumoto \& Minami (1986) e Haag \& Minami
(1988) que estudaram no campo o comportamento da cultivar Folha Larga quanto ao espaçamento e nutrição mineral, respectivamente. Não se conhece estudos sobre a possibilidade do cultivo dessa hortaliça sob cultivo protegido. Por outro lado, produtores de hortaliças sob cultivo protegido, devido a preços insatisfatórios obtidos com pimentão, pepino e tomate, têm procurado alternativas com preferência às hortaliças folhosas de ciclo mais curto, como rúcula, alface, chicória, entre outras. Além disso, a rotação de culturas constitui-se em importante sistema auxiliar no controle de algumas pragas e doenças que incidem em solanáceas e cucurbitáceas. Não se tem informação na região de Campinas sobre o desempenho do almeirão cultivado sob estufa

${ }^{3}$ Comunicação pessoal (HANGUI, A. T., 2001) 
Tabela 1. Comparação entre as cultivares de almeirão Folha Larga, Pão-de-Açúcar e Catalonha e efeito de épocas de avaliação quanto ao número médio de folhas por planta e altura média. Campinas, IAC, 2001.

\begin{tabular}{|c|c|c|c|c|c|}
\hline Cultivares & $\begin{array}{c}N^{\circ} \text { folhas } \\
\text { planta }^{-1}\end{array}$ & $\begin{array}{c}\text { Altura } \\
\text { média }(\mathrm{cm})\end{array}$ & $\begin{array}{c}\text { Dias após a } \\
\text { semeadura }\end{array}$ & $\begin{array}{c}N^{\circ} \text { folhas } \\
\text { planta }^{-1}\end{array}$ & $\begin{array}{c}\text { Altura } \\
\text { média }(\mathrm{cm})\end{array}$ \\
\hline Folha Larga & $6,93 \mathrm{a}^{1}$ & $35,58 \mathrm{~b}$ & 50 & 7,18 & 27,96 \\
\hline Pão-de-Açúcar & $7,05 \mathrm{a}$ & $28,68 \mathrm{c}$ & 57 & 6,83 & 32,24 \\
\hline Catalonha & $7,51 \mathrm{a}$ & $38,87 \mathrm{a}$ & 64 & 7,26 & 36,52 \\
\hline C.V. (A) (\%) & 1,85 & 3,26 & 71 & 7,38 & 40,79 \\
\hline C.V. (B) (\%) & 5,29 & 10,26 & - & - & - \\
\hline
\end{tabular}

${ }^{1 / M e ́ d i a s ~ s e g u i d a s ~ p e l a ~ m e s m a ~ l e t r a ~ n a ̃ o ~ d i f e r e m ~ e n t r e ~ s i ~ p e l o ~ t e s t e ~ d e ~ T u k e y ~ a ~ 5 \% ~ d e ~ p r o b a b i l i d a d e . ~}$

agrícola no final do inverno e começo da primavera.

O presente trabalho teve como objetivo avaliar o desempenho das cultivares de almeirão Folha Larga, Pão-deAçúcar e Catalonha, cultivadas sob estufa agrícola na região de Campinas, quanto ao desenvolvimento e produção em quatro épocas de colheita distintas, visando determinar um ponto de colheita adequado para a sua comercialização.

\section{MATERIAL E MÉTODOS}

O experimento foi instalado no IAC, em Campinas, em estufa com cobertura plástica de polietileno transparente, com trama de $150 \mathrm{~mm}$, e com laterais cobertas com tela tipo sombrite de $2 \mathrm{~mm}$ de abertura, desde a superfície do solo até dois metros de altura. O solo foi classificado como Latossolo Vermelho escuro, distrófico. Os resultados das análises químicas de amostras coletadas na área do experimento foram: matéria orgânica: 28 g/dm $\mathrm{dm}^{3}$ pH em $\mathrm{CaCl}_{2 .}$ 6,0; P: $31 \mathrm{mmol} / \mathrm{dm}^{3} ; \mathrm{K}: 5,3 \mathrm{mmol} / \mathrm{dm}^{3} ; \mathrm{Ca}$ : $26 \mathrm{mmol} / \mathrm{dm}^{3} ; \mathrm{H}+\mathrm{Al}: 25 \mathrm{mmol} / \mathrm{dm}^{3}$; CTC: 64 mmol $/ \mathrm{dm}^{3}$; V: $61 \%$; S: $9 \mathrm{mg} /$ $\mathrm{dm}^{3}$; Na: $3 \mathrm{mg} / \mathrm{dm}^{3}$; Fe: $97 \mathrm{mg} / \mathrm{dm}^{3} ; \mathrm{Mn}$ : $80 \mathrm{mg} / \mathrm{dm}^{3}$; $\mathrm{Cu}: 6 \mathrm{mg} / \mathrm{dm}^{3} ; \mathrm{Zn}: 5 \mathrm{mg} /$ $\mathrm{dm}^{3}$ e B: $0,3 \mathrm{mg} / \mathrm{dm}^{3}$

Logo após a colheita do tomate tipo cereja, o solo para o cultivo do almeirão foi preparado com rotativa manual, incorporando-se, um mês antes do plantio, $100 \mathrm{~g} / \mathrm{m}^{2}$ de calcário dolomítico e $100 \mathrm{~g} /$ $\mathrm{m}^{2}$ de termofosfato. Um mês após a incorporação, foi semeado o almeirão nesse local. Aos 15 dias após a germinação, foram aplicados em cobertura, $3 \mathrm{~g}$ de N/ $\mathrm{m}^{2}$ na forma de sulfato de amônio.

$\mathrm{O}$ experimento foi disposto em blocos ao acaso, com as parcelas subdividi-

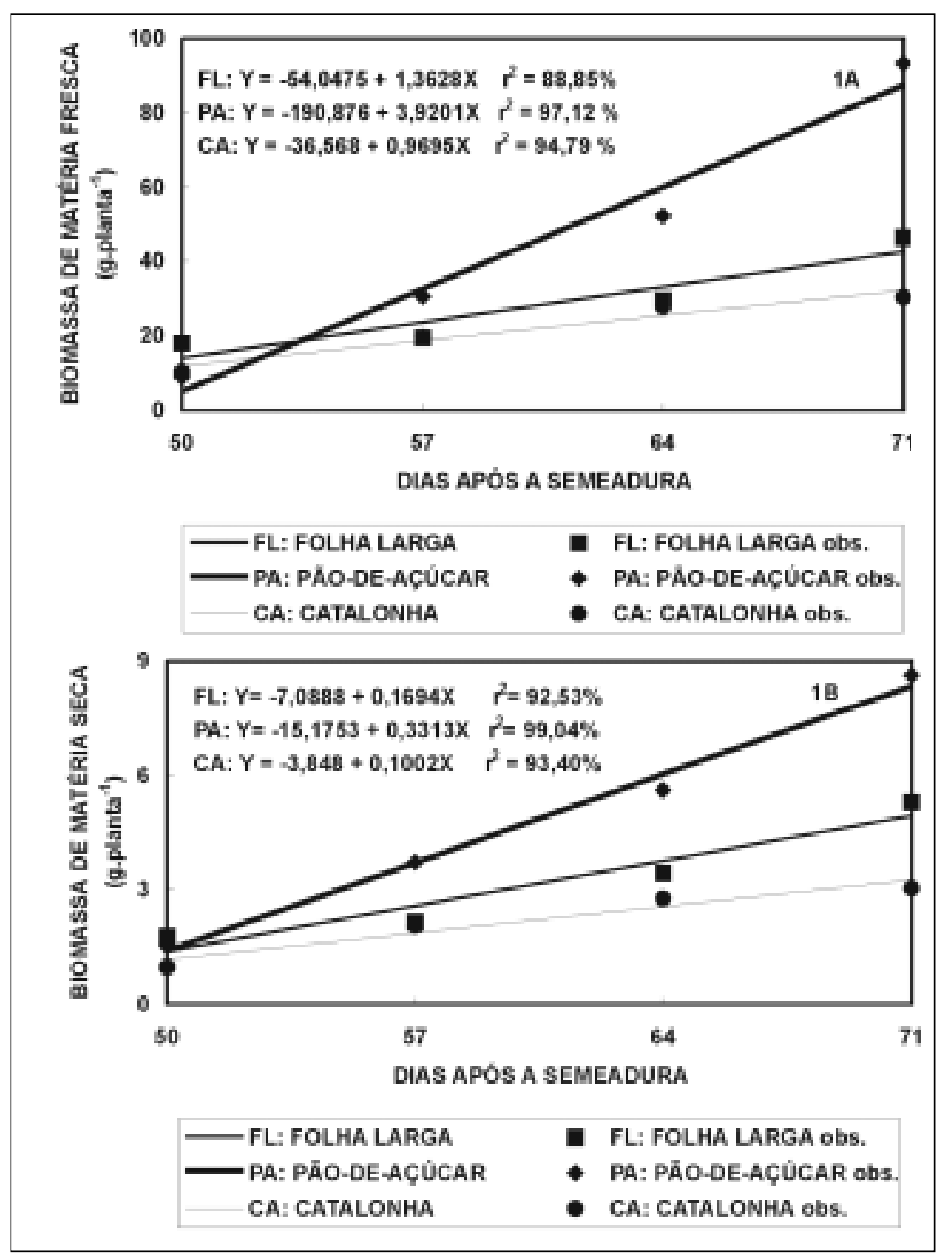

Figura 1. Efeito de época de avaliação para as cultivares de almeirão Folha Larga, Pão-de-Açúcar e Catalonha quanto às biomassas de matéria fresca (1a) e seca (1b). Campinas, IAC, 2001.

das para época de avaliação, com três repetições. As parcelas eram constituídas de trinta e seis linhas de um metro de comprimento, espaçadas em $0,20 \mathrm{~m}$ sen- do os tratamentos as cultivares de almeirão Folha Larga, Pão-de-Açúcar e Catalonha. As linhas das parcelas foram sorteadas a priori para as diferentes épo- 
Tabela 2. Comparação entre as cultivares de almeirão Folha Larga, Pão-de-Açúcar e Catalonha nas diferentes épocas de avaliação quanto à área foliar por planta. Campinas, IAC, 2001.

\begin{tabular}{lccc}
\hline \multirow{2}{*}{ Dias apósa semeadura } & \multicolumn{3}{c}{ Área foliar $\mathbf{( c m}^{2}$.planta- $\left.{ }^{-1}\right)$} \\
\cline { 2 - 4 } & Folha Larga & Pão-de-Açúcar & Catalonha \\
\hline 50 & $480,90 \mathrm{a}^{1}$ & $667,09 \mathrm{a}$ & $364,78 \mathrm{a}$ \\
57 & $481,54 \mathrm{~b}$ & $1426,64 \mathrm{a}$ & $409,01 \mathrm{~b}$ \\
64 & $852,40 \mathrm{ab}$ & $1279,58 \mathrm{a}$ & $603,50 \mathrm{~b}$ \\
71 & $508,86 \mathrm{~b}$ & $1941,69 \mathrm{a}$ & $428,90 \mathrm{~b}$ \\
$\mathrm{a}^{2}$ & - & $-1849,0138$ & - \\
$\mathrm{bx}$ & - & 52,5250488 & - \\
$\mathrm{r}^{2}$ & - & 81,88 & - \\
\hline $\mathrm{CV}(\mathrm{A})$ & - & 12,82 & \\
\hline $\mathrm{CB}(\mathrm{B})$ & \multicolumn{4}{c}{29,90} \\
\hline
\end{tabular}

${ }^{1 /}$ Médias seguidas pela mesma letra, na horizontal, não diferem entre si pelo teste de Tukey a $5 \%$.

2/"'a" e " bx"” são os coeficientes da equação de regressão linear.

${ }^{3 /}$ Coeficientes de determinação (\%) da equação de regressão linear.

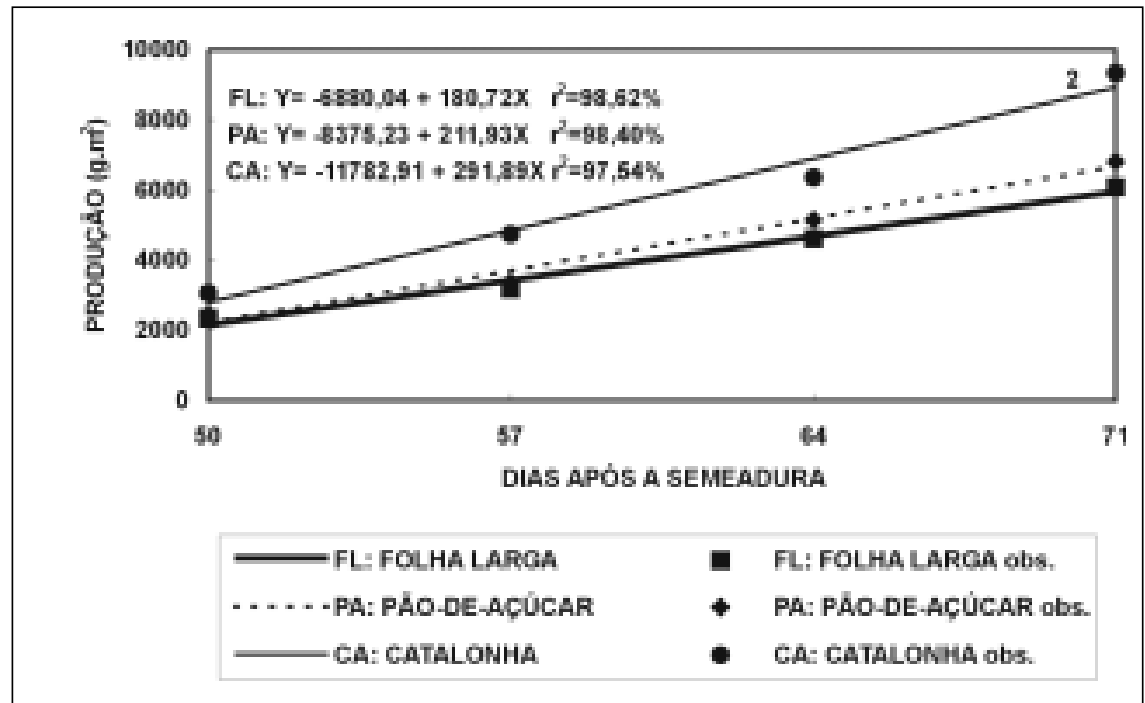

Figura 2. Efeito da época de avaliação nas cultivares Folha Larga, Pão-de-Açúcar e Catalonha quanto à produção. Campinas, IAC, 2001.

cas de avaliação e constituíram as subparcelas. As avaliações foram realizadas aos 50; 57; 64 e 71 dias após a semeadura (DAS).

As sementes, importadas da Itália por empresas nacionais, estavam com 89; 79 e $85 \%$ de germinação para Folha Larga, Pão-de-Açúcar e Catalonha, respectivamente. A semeadura foi realizada em 17 de julho de 2001, a lanço dentro da linha, sendo empregado $0,2 \mathrm{~g}$ de semente $/ \mathrm{m}^{2}$. Quando as plantas estavam com $5 \mathrm{~cm}$ de altura, foi realizado desbaste sendo deixado $3 \mathrm{~cm}$ entre plantas. Devido à necessidade de utilização intensiva de plantas, sob condições de estufa, tem-se procurado realizar plantio gando-se o teste de Tukey para a comparação entre as médias das cultivares e regressão polinomial para os efeitos de épocas. Os dados de número médio de folhas foram transformados em raiz de $\mathrm{X}$ para análise estatística.

\section{RESULTADOS E DISCUSSÃO}

Não houve diferença estatística quanto ao número médio de folhas de almeirão por planta (Tabela 1). Vaz \& Junqueira (1998) também observaram que não havia diferença entre as cultivares de alface Elisa e Verônica Crespa, sob cultivo hidropônico, nos meses de abril a junho de 1997, quando avaliouse o número médio de folhas. Quanto à altura de plantas, verificou-se que houve diferença apenas quando as cultivares foram comparadas entre si e dentro de cada época de avaliação (Tabela 1). A cultivar Catalonha foi superior à Folha Larga e esta à Pão-de-Açúcar. Verificou-se também que a altura média das plantas aumentou linearmente em função do tempo.

As biomassas de matéria fresca e seca mostraram a mesma tendência: em ambas não houve diferença entre as cultivares até 50 DAS mas, a partir dos 57 até os 71 DAS, a 'Pão-de-Açúcar' mostrou ser superior às demais (Figuras $1 \mathrm{a}$ e 1b). Quanto ao efeito de época de avaliação dentro de cada cultivar, verificouse que, tanto a biomassa de matéria fres- 
ca como a seca aumentaram linearmente com o tempo. Esse resultado demonstrou ser útil por permitir retardar um pouco a colheita do material visando obter mais peso, o que acarreta maior lucro para o produtor.

Aos 57 e 71 DAS, a área foliar da 'Pão-de-Açúcar' foi superior às demais (Tabela 2). Aos 64 das, a área foliar da 'Pão-de-Açúcar' não diferiu estatisticamente da 'Folha Larga' mas foi superior à 'Catalonha'. Quanto à época de avaliação, verificou-se que houve efeito apenas para a 'Pão-de-Açúcar'. A área foliar dessa cultivar aumentou linearmente com o tempo apresentando um ajuste de $81,88 \%$.

Embora a partir dos 57 DAS a 'Pãode-Açúcar' tenha apresentado biomassa fresca e seca das folhas superior às demais cultivares (Figura 1), quando avaliou-se a produção em um metro linear, verificou-se que em todas as épocas, a 'Catalonha' foi superior (Figura 2). A menor área foliar da 'Catalonha' (Tabela 2) nas diferentes épocas de avaliação, foi compensada por nervuras e hastes mais espessas e por sua maior altura o que não foi observado quando avaliouse a biomassa individual de dez plantas. Verificou-se também que embora tenha sido feito desbaste para manter o mesmo número de plantas por linha, as cultivares Folha Larga e Catalonha desenvolveram-se apenas verticalmente. A
'Pão-de-Açúcar' apresentou crescimento lateral, formando "cabeça". Devido ao crescimento lateral, verificou-se que houve competição entre plantas dessa cultivar o que ocasionou redução no estande indicando ser necessário maior distância entre plantas de almeirão 'Pãode-Açúcar', em relação à 'Folha Larga' e à 'Catalonha'. Em todos as cultivares avaliadas, a produtividade aumentou linearmente com o tempo (Figura 2). Entretanto, não se recomenda colher almeirão depois de 64 DAS visto que a 'Catalonha' e a 'Folha Larga' apresentaram menor área foliar aos 71 DAS. Nessa amostragem, já se observava ataque inicial de míldio o que poderia depreciar a qualidade do produto.

\section{AGRADECIMENTOS}

Os autores agradecem ao $\mathrm{Sr}$. Lourival Francisco da Silva, funcionário do Centro de Horticultura do IAC pelo apoio na realização dos trabalhos de campo e à Leonilda da Silva Gouvêa do Centro de Fitossanidade do IAC, pelo auxílio na colheita.

\section{LITERATURA CITADA}

CAMARGO, A.M.M.P.; CAMARGO FILHO, W.P. Mercado regional de hortaliças e Mercosul: ações do governo em economia globalizada. Informações Econômicas, São Paulo, v. 29, n. 12, p. 35-48, 1999.
CAMARGO, L.S. As hortaliças e seu cultivo. $3^{\text {" }}$ edição, revista e atualizada. Campinas: Fundação Cargill, 1992. p. 97.

FILGUEIRA, F.A.R. Novo manual de olericultura: agrotecnologia moderna na produção e comercialização de hortaliças. Viçosa: UFV, 2000. p. 294-295.

HAAG, H.P.; MINAMI, K. Nutrição mineral de hortaliças. LXXV - Absorção de nutrientes pela cultura do almeirão. Anais da Escola Superior de Agricultura Luiz de Queiróz, v. 45, parte II, p. 597 603, 1988.

KHATHOUNIAN, C.A. Almeirão: minha doce vida amarga. Agroecologia, v. 2, n. 8, p. 11-12, 2001.

MATSUMOTO, N.S.; MINAMI, K. Efeitos de espaçamentos entre-linhas e da densidade de semeadura na produção de almeirão (Cichorium intybus) no inverno. Solo, v. 78, p. 11-14, 1986.

STEEL, R.G.D.; TORREI, J.H. Analysis of variance. IV: Split-plot designs and analysis. In: STEEL, R.G.D.; TORREI, J.H. (Eds). Principles and procedures of statistics. $2^{a}$ ed. New York: Mc Graw Hill, 1980. p. 377-400. (Capítulo, 16).

TRANI, P.E.; PASSOS, F.A. Almeirão. In: FAHL, J.I.; CAMARGO, M.B.P.; PIZZINATTO, M.A.; BETTI, J.A.; MELO, A.M.T.; DEMARIA, I.C.; FURLANI, A.M.C. Instruções agrícolas para as principais culturas econômicas. 6 ed. Campinas: Instituto Agronômico, 1998. p.178-179. (Boletim, 200).

VAZ, R.M.R.; JUNQUEIRA, A.M.R. Desempenho de três cultivares de alface sob cultivo hidropônico. Horticultura brasileira, Brasília, v. 16, n. 2, p. 178-180, 1998. 